\title{
Some Observations on the Age at Onset of Leprosy
}

\author{
DR. A. K. VARMA, M.D. \\ Lecturer, Preventive and Social Medicine, College of Medical Sciences, \\ Banaras Hindu University, Varanasi, India
}

DR. B. G. PRASAD, M.D., D.P.H., D.T.M.

Professor, Social and Preventive Medicine, King George's Medical College, Lucknow, India

(From the Department of Social and Preventive Medicine, K.G. Medical College, Lucknow)

Age at onset in leprosy still remains disputed and has not received the attention it deserves. There is a wide variability of results among the various authors. The age at onset is important for early diagnosis and treatment and will define the period which should receive the special attention of the public health workers for prevention and control of leprosy. While interpreting the age at onset, a careful interrogation of relatives or friends is essential for those patients who are unable to give correct dates due, to low levels of intelligence, poor or failing memory or for those who cannot give their correct ages.

The present study in Lucknow was carried on outpatients'* new patients coming from the city itself or nearby adjoining areas. The lepromatous rate in Northern India has been reported to vary from 20 to $25 \%$ or even $30 \%$ (Mulick et al., 1957; Chandy et al., 1963; Sharma and Prasad, 1964).

\section{RESULTS}

The age at onset by sex and type found in the present study is given in Table 1 and 2 respectively.

Nearly one-fourth of the total patients $(28.8 \%)$ were below 20 years of age; also in the 2 sexes and among the lepromatous and nonlepromatous the distribution was the same. $9.2 \%$ of patients were 50 years of age or above (Table 2).

Nearly half of the patients $(45.2 \%)$ were in the 15-29 years of age group, below and above which decline was noted (Table 1 ).

Table 3 and the frequency polygon depict comparison of the age at onset reported by Cochrane (1947, quoted by Badger, 1959) and Mohd. Ali (1964) in Madras State said to be highly endemic; Badger (1959) from the endemic states of U.S.A.; study by the present authors at Lucknow reported to have low endemicity; and by Sharma and Prasad (1964) at Barabanki which adjoins Lucknow but has relatively a higher endemnicity.

Cochrane (1947, quoted by Badger, 1959) states 'it is our firm conviction that the great majority of those acquiring leprosy are infected and show manifestations of the disease before the age of $15^{\prime}$. Muir (1948, quoted by Badger, 1959 ) is of the view that 'like tuberculosis infection, leprosy is most common in the first few years of life'. Rogers and Muir (1946, quoted by Badger, 1959) hold that children and young adults up to the age of 20 years are most susceptible to infection by leprosy, while Doull (1957, quoted by Badger, 1959) holds that 'greater susceptibility of young children is indicated by their relative higher risk when exposed in the household'. Mohd. Ali (1964) on the contrary holds that, assuming 10 years as the incubation period, about $50 \%$ of patients under his study (i.e., 1,760 patients) had got infected

Refers to outpatients' department of Leprosy Hospital, Nishatganj, Lucknow, where the study was carried out and the present enquiry comprised of a part of thesis for M.D. examination of Lucknow University by the first author. 
Táele 1

Distribution of age at onset* by sex and type

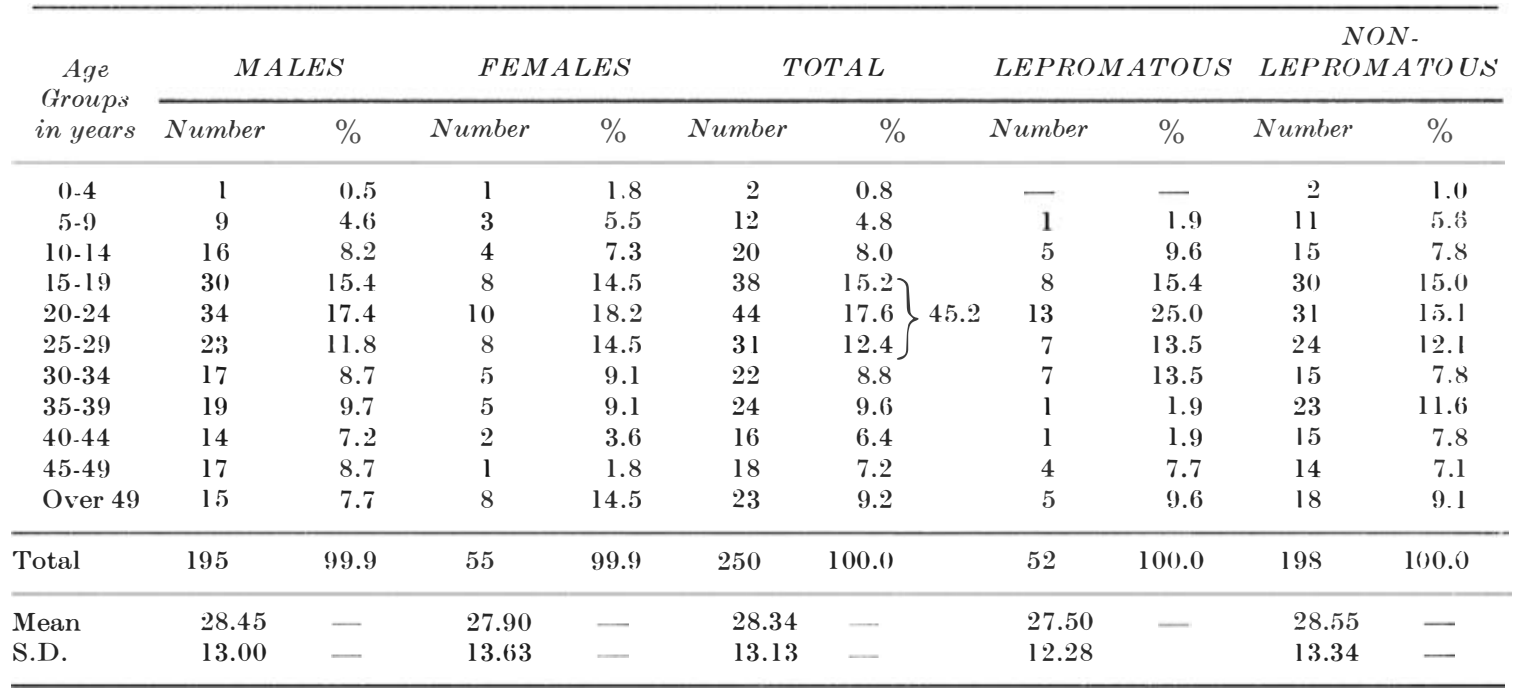

* The age at onset has been worked out on the basis of deducting probable duration of disease from the present age (i.e., what the patient has reported in the outpatients' department).

TABLE 2

Percentage distribution of age at onset for the three distinct age groups (by sex and type)

\begin{tabular}{lccccc}
\hline \multirow{2}{*}{$\begin{array}{c}\text { Age groups } \\
\text { in years }\end{array}$} & \multicolumn{2}{c}{ DISTRIBUTION } & BY SEX & \multicolumn{2}{c}{ DISTRIBUTION BY TYPE } \\
\cline { 2 - 6 } & Males & Females & Total & Lepromatous & Non-Lepromatous \\
\hline $0-19$ & 28.7 & 29.1 & 28.8 & 26.9 & 29.4 \\
$20-49$ & 63.3 & 56.3 & 62.0 & 63.5 & 61.5 \\
50 years and over & 7.7 & 14.5 & 9.2 & 9.6 & 9.1 \\
\hline
\end{tabular}

after they had passed their 20th year of life thereby showing that leprosy is not a children's disease.

The results of the present study are similar to those undertaken in the U.S.A. (Badger, 1959) where the rising trend is more marked and sustained with advancing years of life (Table 3). Higher percentage of population of the older age groups in the U.S.A. may account for this difference.

Figures of the 2 studies undertaken in a highly endemic area, i.e., the Madras State, by Cochrane (1947, quoted by Badger, 1959) and Mohd. Ali (1964) at different periods, indicate the age of onset to be below 10 years of age in nearly 15 to $20 \%$ of the patients. Comparative figures by different authors in Table :3 for the lesser endemic areas of U.P. and U.S.A. vary from 3 to $5 \%$, about 3 times less than the figures found in the Madras State, showing thereby an earlier age predisposition in highly endemic zones.

It is worth while to observe that $41.3 \%$ of the patients fell in the 10 years age group of 15-24 years in Cochrane's Madras study (Cochrane, 1947, quoted by Badger, 1959), $51.8 \%$ in the 20 years age group of 20-39 years in that of Sharma and Prasad (1964), $42.5 \%$ in the 25 years age group of 25-49 in Mohd. Ali's (1964) study in Chingleput (Madras State), $44.4 \%$ in the 25 years age group of $25-49$ years in the present study, and $45 \%$ in the 25 years age group

\section{2:36 Leprosy Revieu,}


TABLE 3

Showing comparative study of percentage distribution of age at onset in different areas by different workers

\begin{tabular}{|c|c|c|c|c|c|}
\hline $\begin{array}{l}\text { Age at onset } \\
\text { in years }\end{array}$ & $\begin{array}{c}\text { Madras State } \\
\text { (Cochrane, } 1947 . \\
\text { quoted by } \\
\text { Badger, 1959) }\end{array}$ & $\begin{array}{c}\text { Chingle put } \\
\text { District of } \\
\text { Madras Siate } \\
\text { (Mohd. Ali, 1964) }\end{array}$ & $\begin{array}{c}\text { Lucknow Study } \\
\text { (Present } \\
\text { authors) }\end{array}$ & $\begin{array}{c}\text { Barabanki Study } \\
\text { (Sharma and Prasad, } \\
1964)\end{array}$ & $\begin{array}{c}\text { Endemic siuie. } \\
\text { of USA } \\
\text { (Badger, } 1959\end{array}$ \\
\hline $0-4$ & 6.3 & 3.8 & 0.8 & 1.2 & 0.1 \\
\hline $5-9$ & 13.4 & 11.3 & 4.8 & 2.4 & 3.0 \\
\hline $10-14$ & 15.9 & 11.0 & 8.0 & 4.8 & 7.0. \\
\hline $15-19$ & $19.8\}_{413}$ & 9.5 & 15.2 & 9.6 & 13.2 \\
\hline $20-24$ & $21.5\}^{41.3}$ & 12.2 & 17.6 & $20-29$ yrs. 25.3$\}$ & 13.4 \\
\hline $25-34$ & 16.1 & $21.6\}_{4}$ & $21.2\}$ & $30-39$ yrs. 26.5$\}$ & $19.8\}_{15}$ \\
\hline $35-49$ & 7.0 & $20.9\}^{42.5}$ & $23.2 \int^{44}$ & $40-49$ yrs. 16.9 & $25.2\}^{45.0}$ \\
\hline 50 years and above & & 10.4 & 9.2 & 13.2 & 17.8 \\
\hline Under 10 & 19.7 & 15.1 & 5.6 & 3.6 & 3.1 \\
\hline Under 20 & 55.4 & 356 & $\therefore 8.8$ & 18.0 & 28.3 \\
\hline Over 10 & 80.3 & 84.9 & $n 14$ & 96.4 & 96.4 \\
\hline Over 20 & 44.6 & 64.4 & $71 \cdot 2$ & 81.9 & 76.3 \\
\hline Over 35 & 7.0 & 31.3 & 32.4 & 30.1 & 43.0 \\
\hline Over 49 & & 10.4 & 9.2 & 13.2 & 17.8 \\
\hline
\end{tabular}

FREQUENCY POLYGON SHOWING PERCENTAGE DISTRIBUTION OF

AGE OF ONSET IN DIFFERENT AREAS BY DIFFERENT WORKERS

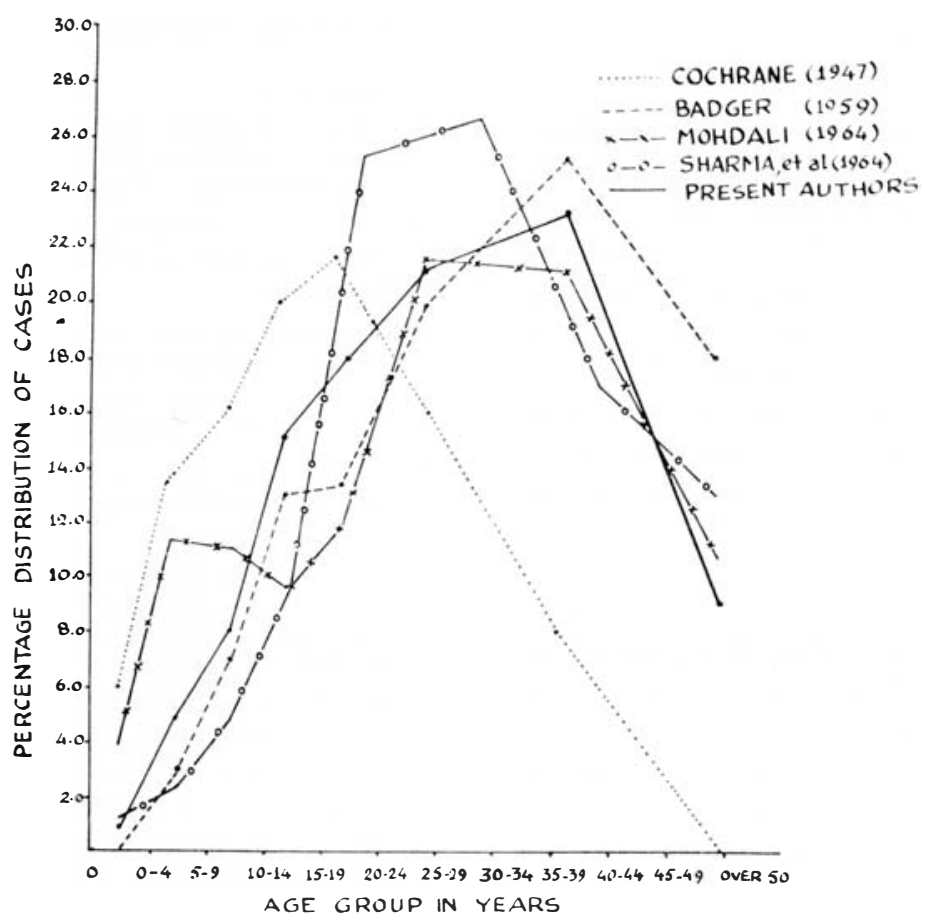

Some Observations on the Age of Onset of Leprosy $2: 37$ 
of 25-49 years in the U.S.A. study (Badger, 1959). Thus in nearly $40-50 \%$ of the total number of patients the age at onset was in young or younger age groups in the studies under reference and the greater the endemicity the lower was the age of onset.

It will be seen from the above that there is a variation in the age at onset in the two Madras studies (Cochrane, 1947, quoted by Badger, 1959; and Mohd. Ali, 1964) and the 2 studies undertaken in Uttar Pradesh (Sharma and Prasad, 1964, and the present study). According to Badger (1959), the age of onset is seen to vary in different countries, in different parts of the same country and even in the same areas at different times.

Further, in a much larger percentage of patients the age at onset was found at a lower age in childhood, i.e., below 10 years in Madras studies, while the figures in studies from Uttar Pradesh fell between the Madras and the U.S.A. studies. It was revealed in the present study that in the majority of instances the infectisus contact was a result of infection from without the household in those giving positive histories of contact (Varma, 1964). This was also the finding of Sharma and Prasad (1964).

All the above mentioned studies show that $30-40 \%$ of patients reported the age at onset after they had passed their 35th year of life, excepting in Cochrane's study (1947, quoted by Badger, 1959) where it was $7 \%$. Mohd. Ali (1964) refers to the incubation period of leprosy as a subject of much controversy-Rogers (quoted by Mohd. Ali, 1964) suggesting 3-5 years, Badger (1959) 3-4 years, recent Japanese studies (quoted by Mohd. Ali, 1964) putting it at 8 years, and the longest perhaps up to 20 years (Dharmendra, 1960). 23.2\% of patients reported the age at onset falling within the age group between 35-49 years and 9.2\% above 49 years in the present study. With regard to the patients in these 2 later groups there can be little doubt that they could not have developed the disease consequent to childhood infection.

In the absence of reliable diagnostic tests for estimation of immunity to leprosy and in- dividual resistance patterns (variable response to infection) it would not be safe to propose a fixed limit for the age at onset. Moreover, principles of universal acceptability cannot be formulated especially when the country presents widely differing spectra of psycho-socio-cultural and economic strata (Varma and Prasad, 1966). However, the vulnerability to infection as evinced by variability in age at onset is suggestive of the involvement of multiple factors (individual as well as community factors). The community infection, i.e., availability of infectious contacts to susceptible hosts, probably determines the childhood, adult or geriatric predominance.

\section{SUMMARY}

The authors have attempted to analyse the age at onset reported by various workers the world over along with their own findings. They suggest that the availability of infectious contacts probably determines the age at onset in a community. There is ample evidence to suggest that adulthood infection is by no means as rare as it is often thought to be.

It may not be safe to suggest a definite age at onset in the absence of reliable tests for determining immunity status.

\section{REFERENCES}

BADGeR, L. F. (1959). Leprosy in Theory and Practice, edited by Cochrane, R. G. (1959), pp. 51-77, chapter vi, Epidemiology. John Wright and Sons, Bristol.

CHANDY, P. T., PATRICK, G. S. and BRAMWELL, F. E. (1963). Leprosy in Uttar Pradesh. Lep. in India. $35,128-131$.

DHARMEndra (1960). Notes on Leprosy, p. 10. The Ministry of Health, Government of India.

монд ALI, P. (1964). The Age at Onset of Leprosy. Lep. Rev., 35, 4, 193-197.

MULlick, D. K., SEN, S. C. and SEN, P. (1957). The Bankura Rural Leprosy Investigation Centre. Lep. in India, 29, 89-97.

ShARMA, v. K. and PRASAD, B. G. (1964). An Epidemiological Study of Leprosy in Masauli Block of Bara banki District, Uttar Pradesh. Ind. Jour. Med. Res., 52, 1293-1312.

VARMA, A. K. (1964). A Study of Leprosy amon« Patients attending a Leprosy Hospital at Lucknow: Thesis for M.D., Lucknow University (unpublished).

VARMA, A. K. and PRASAD, B. G. (1966). Role of education in health programmes with reference tn leprosy control. Ind. Jour. Pub. Hlth., Conf. No., 10, $1,26$. 